\title{
PENGARUH LATIHAN SINGLE LEG HOPS TERHADAP HASIL LOMPAT JANGKIT SISWA SMP 1 SUNGAI LILIN
}

\author{
Sugarwanto \\ Universitas PGRI Palembang, email : Sugar.wanto88@gmail.com
}

\section{Ardo Okilanda}

Universitas Negeri Jakarta, email : ardookilanda_por16s3@mahasiswa.unj.ac.id

\begin{abstract}
Abstrak
Dalam artikel ini latihan Single Leg Hops dapat meningkatkan kemampuan Lompat jangkit, sehingga setelah diberikan latihan Single Leg Hops siswa bisa meningkatkan kemampuan Lompat jangkit. Siswa dapat melakukan teknik lompat jangkit dengan baik, sehingga memudahkan siswa melakukan Lompat jangkit. Tujuan artikel ini adalah mengetahui pengaruh signifikan latihan Single leg Hops terhadap hasil Lompat jangkit pada siswa putra kelas IX SMP Negeri 1 sungai lilin Indonesia. Metode yang dipakai adalah pre-experimental designs (non designs) teknik pengumpulan data dilakukan dengan instrumen tes lompat jangkit. Sampel diberi latihan single leg hops selama 6 minggu dengan frekuensi 3 kali seminggu. Analisis data menggunakan statistik uji t. Hasil analisis data didapatkan bahwa rata-rata tes awal lompat jangkit sebelum diberikan latihan single leg hops adalah sebesar 3,061 meter. Sedangkan rata-rata tes akhir lompat jangkit setelah diberikan latihan single leg hops sebesar 3,180 meter. Kesimpulan dari artikel ini bahwa ada pengaruh latihan single leg hops terhadap hasil lompat jangkit pada siswa putra kelas IX SMP Negeri 1 sungai lilin dan latihan yang diberikan hendaknya mengarah kepada gerakan seperti pada pertandingan lompat jangkit.
\end{abstract}

Kata kunci : Latihan Single leg hops, Lompat jangkit, atletik.

\begin{abstract}
This article discuss about single leg hops training to improve triple jump skill, so that after give single leg hops, students will improve their outbreak ability. Students can do the triple jump technique well. The objective of this article is find out the significant influence of Single Leg Hops toward triple jump result on the male students of nine grader State Junior High School 1 of Sungai Lilin, Indonesia. This article is using pre-experimental designs in collecting the data. This method is using triple jump test as instrument. The samples are giving single leg hops in 6 weeks with frequency of 3 times a week. The data analysis is using t test statistic. The result shown pre-test average result of triple jump before applied single leg hops is 3,061 meters. Whereas the post-test average result of triple jump after applied single leg hops is 3.180 meters. The conclusion is an influence of single leg hops training toward triple jump result of the male students of nine graders of State Junior High School 1 Sungai Lilin. The training should lead on the triple jump competition movement.
\end{abstract}

Keywords : Single leg hops training, triple jump, atletic 


\section{PENDAHULUAN}

Cabang olahraga yang tertua yaitu atletik disebut juga sebagai Ibu atau induk dari semua cabang olahraga. Cabang olahraga ini juga mendapat julukan Mother of The Sport. Sebagai induk dari seluruh cabang olahraga atletik memiliki cabang yang bisa dipertandingkan dalam setiap pertandingan olahraga di seluruh dunia. Atletik di Indonesia populer melalui penjajah Belanda di mana pada waktu itu atletik dijadikan sebagai salah satu mata pelajaran di jenjang pendidikan sekolah.

Cabang olahraga atletik adalah sebuah cabang yang dipertandingkan baik ditingkat daerah, regional kab/kota dan propinsi, nasional dan juga internasional, karena atletik sebuah cabang olahraga yang terbagi atas banyak nomor yang dapat diperlombakan terdiri dari: (1) nomor jalan terdiri dari jalan santai dan jalan cepat, (2) nomor lari terdiri dari sprint, estafet, lari gawang, marathon dan halang rintang, (3) nomor lompat terdiri dari lompat jauh, lompat tinggi, lompat jangkit dan lompat galah, dan (4) nomor lempar terdiri dari lempar lembing, lempar cakram, tolak peluru dan lempar martil.

Lompat jangkit adalah salah satu nomor lompat dalam cabang olahraga atletik. Lompat jangkit diikutsertakan dalam pesta Olimpiade pada tahun 1896 dan hingga baru-baru ini masih merupakan nomor untuk putra. Sekarang, lomba lompat jangkit diadakan untuk putra dan putri. Seperti lompat jauh, lompat jangkit membutuhkan kecepatan dan kelenturan, namun kedua nomor tersebut berbeda dimana lompat jangkit melibatkan tiga lompatan berurutan, yang semuanya saling berkaitan. (Carr, 2003). Sesuai dengan namanya, maka Lompat jangkit atau sering disebut juga lompat tiga, dalam bahasa inggrisnya disebut triple jump. Dikatakan juga lompat tiga karena lompat jangkit ini terdiri dari tiga lompatan yaitu jangkit, langkah dan lompat. Dalam bahasa inggris disebut hop, step, jump. (Suherman, 2001). Dalam lompat jangkit diperlukan lebih banyak Power dan stamina daripada lompat jauh. Hal ini karena dalam lompat jauh atlet hanya melakukan satu kali tolakan untuk memperoleh jarak sejauh-jauhnya, sedangkan dalam lompat jangkit atlet melakukan tiga tolakan untuk memperoleh jarak sejauh-jauhnya. Sehingga dengan demikian dalam lompat jangkit atlet harus mempunyai stamina dan power yang lebih banyak agar ia mampu melakukan tiga kali tolakan secara berturut-turut dengan efektif, (Suherman, 2001).

Untuk meningkatkan power dibutuhkan latihan yang baik dan sesuai dengan aspek-aspek fisik dan prinsip-prinsip latihan. Salah satu bentuk latihan untuk meningkatkan power adalah Single Leg Hops. Latihan Single Leg Hops (Melompat Dengan Satu Kaki) adalah bentuk latihan plyometrics dengan melompat menggunakan satu kaki. Menurut (Jarver,1999) "Latihan melompat dengan satu kaki bertujuan mengubah gerakan lari menjadi suatu Hop yang rendah menurut suatu lintasan, dengan sedapat mungkin tetap mempertahankan kecepatan Horisontal". Untuk melakukan gerakan seperti yang dijelaskan oleh (Chu,1992) "stand on one leg push off the standing leg and jump forward, landing on the same leg. use a strong leg swing to increase jump length and strive for height. immediately take off again and continue for 10 to 25 meters. perform this drill with the other leg for symmetrical developtment. beginning athletes will use a straighter jump leg; advanced athletes should try to pull the heel toward the buttocks during the jump". (berdiri dengan satu kaki mendorong dari kaki berdiri dan melompat ke depan, mendarat dikaki yang sama. Menggunakan ayunan kaki yang kuat untuk meningkatkan panjang melompat dan berusaha untuk tinggi. Segera lepas landas lagi dan terus 
selama 10 sampai 25 meter. Melakukan latihan ini dengan kaki lainnya untuk pengembangan simetris. Atlet mulai akan menggunakan kaki lurus melompat; atlet maju harus mencoba untuk menarik tumit ke arah pantat selama melompat).

Tujuan dari artikel ini adalah untuk mengetahui apakah terdapat pengaruh antara latihan single leg hops terhadap hasil lompat jangkit pada siswa putra kelas IX SMP Negeri 1 sungai lilin Indonesia.

\section{METODE}

Metode yang dilakukan dengan metode pre-experimental designs (non designs). Desain ini merupakan upaya atau cara yang dipakai dalam melaksanakan sebuah perlakuan untuk memperolah hasil test. Dilakukan pre test (sebelum diberi perlakuan) dan post test (setelah dilakukan perlakuan). Hasil perlakuan dapat dik lebih akurat karena dapat membandingkan dengan keadaan sebelum diberikan perlakuan (Sugiyono, 2011). Variabel bebas (X) adalah latihan single leg hops dan variabel terikat $(\mathrm{Y})$ adalah hasil lompat jangkit.

Populasi seluruh siswa kelas IX di SMP Negeri 1 sungai lilin. Teknik pengambilan sampel menggunakan teknik simple random sampling. Simple Random sampling adalah Pengambilan sampel yang dipakai secara acak tanpa memperhatikan strata yang ada dalam populasi untuk dipilih. Jumlah sampel yang diambil 10\% dari 296 siswa dari populasi. Sehingga didapat jumlah sampel sebanyak 30 siswa putera kelas IX SMP Negeri 1 sungai lilin.

Sebelum melakukan tahapan pemberian perlakuan dilakukan test awal terlebih dahulu (pre test), pre test yang dilakukan yaitu instrumen tes lompat jangkit. Setelah mendapatkan hasil pre test dilanjutkan pemberian perlakuan (treatment) yaitu latihan single leg hops. Pada akhirnya dilakukan Tes akhir (post test) melakukan lompat jangkit. Tes dilaksanakan sebanyak 3 kali dan diambil hasil lompatan terjauh.

Teknik Analisis data adalah cara yang digunakan untuk memperoleh atau mengolah data-data yang terkumpul dan diklasifikasikan sesuai dengan tujuan. Maka penulis menggunakan metode statistik. Uji statistik yang dipakai dengan menggunakan uji $t$. selanjutnya siswa diberikan perlakuan (treatment) berupa latihan single leg hops sebanyak 3 kali dalam satu minggu dan dilaksanakan selama 6 minggu. Latihan single leg hops ini bertujuan untuk meningkatkan hasil lompat jangkit pada tes akhir (post-test) yang mengacu pada gerakan pada pertandingan lompat jangkit.

\section{HASIL DAN PEMBAHASAN Hasil}

Hasil yang didapat di SMP Negeri 1 sungai lilin, populasi seluruh siswa putra kelas IX dan sampel adalah siswa putra kelas IX.1 dan IX.2 yang berjumlah 30 orang yaitu 15 orang siswa putra kelas IX.1 dan 15 orang siswa putra kelas IX.2. Desain menggunakan pre-test and post-test one group. Dalam desain ini observasi dilakukan sebanyak 2 kali yaitu sebelum eksperimen dan sesudah eksperimen.

Pengambilan data diperoleh melalui tes awal dan tes akhir dari hasil tes lompat jangkit. Hasil tes awal diperoleh nilai ratarata sebesar 3,061 meter dan tes akhir sebesar 3,180 meter. Setelah dilakukan pengolahan data, diperoleh hasil perhitungan uji normalitas data yaitu tes awal (pre-test) dengan nilai $\mathrm{Km}=-1,712$ dan tes akhir dengan nilai $\mathrm{Km}=-1,909$. Kedua harga tersebut terletak diantara -1 dan +1 , maka kedua data tersebut berdistribusi normal. Berdasarkan hasil analisis data tes awal (pre-test) dan tes akhir (post-test) hasil 
lompat jangkit, rata-rata nilai hasil tes awal (pre-test) lompat jangkit adalah 3,061 meter dan tes akhir (post-test) lompat jangkit sebesar 3,180 meter. Kemudian data hasil tes awal (pre-test) dan tes akhir (post-test) dilakukan uji taraf signifikansi dan diperoleh harga $t_{\text {hitung }}$ sebesar 8,240 dan harga $t_{\text {tabel }}$ sebesar 1,699 . Jadi $t_{\text {hitung }}>t_{\text {tabel, }}$ dengan demikian $\mathrm{H}_{\mathrm{a}}$ diterima dan $\mathrm{H}_{\mathrm{o}}$ ditolak. Ini berarti bahwa ada pengaruh antara latihan single leg hops terhadap hasil lompat jangkit pada siswa putra kelas IX Smp Negeri 1 Sungai Lilin Indonesia.

\section{PEMBAHASAN}

Berdasarkan hasil, maka dapat dikatakan bahwa terdapat hubungan yang signifikan antara latihan single leg hops terhadap hasil lompat jangkit pada siswa putra kelas IX SMP Negeri 1 sungai lilin sesuai dengan gerakan lompat jangkit. Berarti memang latihan single leg hops yang dilakukan siswa putra kelas IX SMP Negeri 1 Sungai lilin Indonesia berpengaruh secara signifikan dengan hasil lompat jangkit. Hal ini sesuai dengan (Jarver,1999) "Latihan melompat dengan satu kaki bertujuan mengubah gerakan lari menjadi suatu Hop yang rendah menurut suatu lintasan, dengan sedapat mungkin tetap mempertahankan kecepatan Horisontal". Untuk melakukan gerakan seperti yang dijelaskan oleh (Chu,1992) "stand on one leg push off the standing leg and jump forward, landing on the same leg. use a strong leg swing to increase jump length and strive for height. immediately take off again and continue for 10 to 25 meters. perform this drill with the other leg for symmetrical developtment. beginning athletes will use a straighter jump leg; advanced athletes should try to pull the heel toward the buttocks during the jump". (berdiri dengan satu kaki mendorong dari kaki berdiri dan melompat ke depan, mendarat dikaki yang sama. Menggunakan ayunan kaki yang kuat untuk meningkatkan panjang melompat dan berusaha untuk tinggi. Segera lepas landas lagi dan terus selama 10 sampai 25 meter. Melakukan latihan ini dengan kaki lainnya untuk pengembangan simetris. Atlet mulai akan menggunakan kaki lurus melompat; atlet maju harus mencoba untuk menarik tumit ke arah pantat selama melompat).

\section{PENUTUP}

\section{Simpulan}

Hasil yang didapat dari data dilakukan uji taraf signifikansi dan diperoleh harga $t_{\text {hitung }}$ sebesar 8,240 dan $t_{\text {tabel }}$ sebesar 1,699, dengan demikian $t_{\text {hitung }}>t_{\text {tabel }}$ maka $\mathrm{H}_{a}$ diterima dan $\mathrm{H}_{\mathrm{o}}$ ditolak. Maka berdasarkan hasil di atas dapat disimpulkan bahwa terdapat pengaruh latihan single leg hops terhadap hasil lompat jangkit pada siswa putra kelas IX SMP Negeri 1 Sungai Lilin Indonesia.

\section{Saran}

Untuk Guru SMP Negeri 1 Sungai Lilin Indonesia, dalam kegiatan pembelajaran penjasorkes diharapkan memberikan kegiatan pembelajaran berbagai latihan seperti latihan single leg hops, double leg hops, skiping, lari zig-zag dan latihann jump to box agar tidak terjadi tingkat kejenuhan pada siswa dalam kegiatan belajar penjasorkes. Bagi siswa SMP Negeri 1 sungai lilin, agar terbiasa menerapkan latihan single leg hops baik disekolah maupun dalam kehidupan sehari-hari dan meningkatkan dan menambah intesitas program latihan sehingga dapat meningkatkan kekuatan otot kaki dan dapat meningkatkan prestasi di seluruh cabang olahraga. 


\section{DAFTAR PUSTAKA}

Ardle, C.C. 2006. Plyometrics Exercise Drills Pliometrics Training Equipment. Diakses: 20 Agustus 2015.http://www.thesstretcinganboo k.com/newslatter.htm.

Carr, A. Gerry. (2003). Atletik Untuk Sekolah. Jakarta : PT Raja Grafindo Persada.

Chu, Donald. (1992). Ather Sports Injury Clinic Castro Valley. California : Human Kinetics.

Dewi, N. K. 2014. Pengaruh Pelatihan Single Leg Speed Hop dan Double Leg Speed Hop Terhadap Daya Ledak Otot Tungkai. Jurnal IKOR Vol 2. Universitas Pendidikan Ganesha.

Doewes, M. 2004. Latihan Pliometrics. Program Pasca Sarjana, Surakarta.

Ebben, W.P. 2007. Practical Guidelines For Plyometric Intensity. NSCA's Performance Training Journal.

Harsono. 2000. Coachingdan aspek-aspek psikologis dalam coaching. Jakarta: Department Pendidikan dan Kebudayaan.

Jarver, Jess. (1999). Belajar dan Berlatih Atletik. Bandung : CV Pionir Jaya.

Kotzmanidis, C. 2006. Effect of Pliometric Training on Running Performance and Vertical Jump Jumping in Prepubertal Boys. J Strenght Cond Res. Volume 7. Nomor 4 May 2006: halaman 236-243.

Lubis, J. 2009. Mengenal Latihan Pliometrik. Jurnal Penelitian Kesehatan. Jakarta: Fakultas IImu Kesehatan, Universitas Negri Jakarta.

Mochamad Djumidar A. Widya. 2004. Gerak-Gerak Dasar Atletik Dalam Bermain. Jakarta : PT Raja Grafindo Persada.

Okilanda, Ardo. (2018). Revitalisasi Masyarakat Urban/Perkotaan Melalui Olahraga Petanque". Halaman Olahraga Nusantara: Jurnal IImu Olahraga 86-98. Tersedia di jurnal.univpgri-

palembang.ac.id/index.php/hon/articl e/view/1505 diakses 28 Februari 2020

Radcliffe, J.C \& Farentinos, R.C. 2002. Plyometrics Explosive Power Training. 2nd ed. Champaign, Illionis: Human kinetics Published, Inc.

Sugiyono. (2011). Metode Penelitian Kuantitatif Kualitatif dan $R \& D$. Bandung : Alfabeta.

Suherman, Adang dkk. (2001). Pembelajaran Atletik Pendekatan Permainan dan Kompetetisi untuk Siswa SMU dan SMK. Jakarta : Direktorat Jendral Olahraga.

Y. Bahagiam, U. Yusup, A. Suherman. 2000. Atletik Departemen pendidikan nasional. 